\title{
Wave conditions in the Baltic Proper and in the Gulf of Finland during windstorm Gudrun
}

\author{
T. Soomere ${ }^{1}$, A. Behrens ${ }^{2}$, L. Tuomi ${ }^{3}$, and J. W. Nielsen ${ }^{4}$ \\ ${ }^{1}$ Centre for Nonlinear Studies, Institute of Cybernetics at Tallinn University of Technology, Tallinn, Estonia \\ ${ }^{2}$ Institute for Coastal Research, GKSS Forschungszentrum, Geesthacht, Germany \\ ${ }^{3}$ Finnish Institute of Marine Research, Helsinki, Finland \\ ${ }^{4}$ Danish Meteorological Institute, Copenhagen, Denmark
}

Received: 15 May 2007 - Revised: 27 September 2007 - Accepted: 10 December 2007 - Published: 21 January 2008

\begin{abstract}
Wave conditions in the northern Baltic Proper during windstorm Erwin/Gudrun (January 2005) are analysed based on in situ measurements in three locations and output of operational wave models from the German Weather Forecast Service, the Danish Meteorological Institute and the Finnish Institute of Marine Research. The measured significant wave height reached $7.2 \mathrm{~m}$ in the northern Baltic Proper and $4.5 \mathrm{~m}$ in the Gulf of Finland. The roughest wave conditions, estimated from the comparison of the forecast and measured data, occurred remote from the sensors, off the coasts of Saaremaa and Latvia where the significant wave height was about $9.5 \mathrm{~m}$. Peak periods exceeded $12 \mathrm{~s}$ in a large part of the northern Baltic Proper and in the central part of the Gulf of Finland.
\end{abstract}

\section{Introduction}

Windstorm Gudrun, an extratropical cyclone, also known as Erwin in Ireland, the United Kingdom and Central Europe, attacked the northern Europe on 7-9 January 2005. It reached the power of a hurricane, according to the SaffirSimpson hurricane scale (Simpson and Riehl, 1981), in the North Sea region. In the Baltic Sea region it remained slightly below the hurricane level; however; it was one of the strongest in Denmark, Scandinavia and Estonia for at least 40 years. Note that the wind speed used for distinguishing the hurricanes in the United States is measured as the average over $1 \mathrm{~min}$ whereas the 10-min average is used in Europe. It caused widespread property damage and exceptionally high floods, and loss of 18 lives (Carpenter, 2005; Suursaar et al., 2006). Forest damage in Sweden was the largest ever reported in Sweden (Bengtsson and Nilsson, 2007). The storm cut down power supply in large areas of Sweden, Norway

Correspondence to: T. Soomere

(soomere@cs.ioc.ee) and the Baltic states. The highest storm surge in the known history ( $275 \mathrm{~cm}$ over the mean sea level) occurred in Pärnu (Suursaar et al., 2006). New records of water level were established in many locations along the Western Estonian coast as well in the Gulf of Finland. The storm induced a major water inflow into the Gulf of Riga and flushed totally smaller shallow areas such as the Moonsund (Väinameri, an area between Saaremaa, Hiiumaa and the Estonian mainland) with the water from the Baltic Proper. Particularly intense transport of bottom sediments apparently took place in certain parts of the sea (Suursaar et al., 2006). Several smaller harbours suffered from massive damage and substantial beach destruction occurred at places (Orviku, 2006). The meteorological conditions, details of accompanying flooding, and the reaction of water masses to this storm in Estonian coastal waters are analysed in detail by Carpenter (2005) and Suursaar et al. (2006).

A major feature of this storm consisted in very rough wave conditions in the northern Baltic Proper and the Gulf of Finland. The combination of rough seas and extremely high water level eventually is the main reason for the extensive property damage in affected coastal areas. Since the network of wave measurements at the downwind side of the northern Baltic Sea (Fig. 1) only consisted of two directional waveriders operated by the Finnish Institute of Marine Research and one pressure-based recorder (while sea level was filed at about 20 sites), it is intuitively clear that the measured wave data only partially reflected the wave situation during this storm. The strongest winds (W-WSW) were oblique to the longest extension of the Baltic Proper (SSW-NNE) and occurred between Gotland and Saaremaa where the fetch is relatively short, in an area much southwards from the wave sensors. Even with these non-ideal conditions for wave generation (compared to a "perfect" storm steadily blowing along the axis of the Baltic Proper), very high and long waves were recorded.

Published by Copernicus Publications on behalf of the European Geosciences Union. 


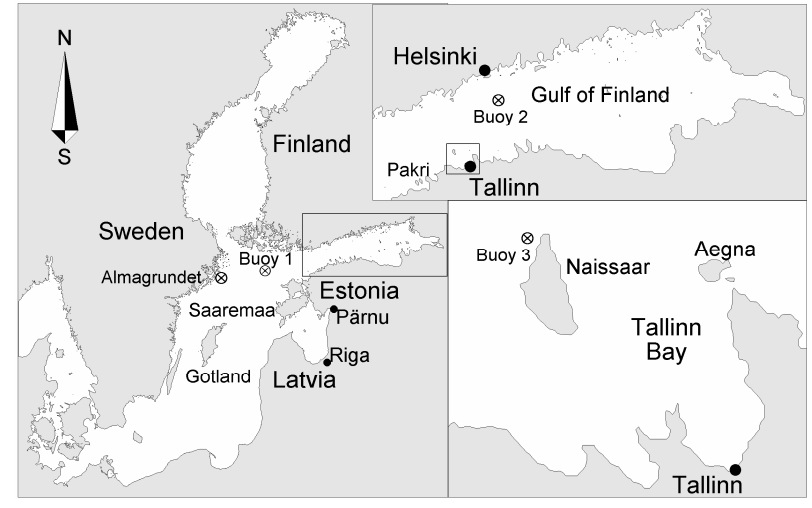

Fig. 1. Wave measurement sites, marked by $\otimes$, in the Northern Baltic Proper, near Helsinki and at the Island of Naissaar.

The purpose of this paper is to estimate the roughest wave conditions during this storm based on available data. The analysis is based on wave measurements in the northern Baltic Proper (NBP) and the Gulf of Finland (GoF), and on the output of operational wave models in the leading operational centres in the Baltic Sea area: the German Weather Forecast Service (DWD, Deutscher Wetterdienst), the Danish Meteorological Institute (DMI), and the Finnish Institute of Marine Research (FIMR). The analysis is performed for the significant wave height but the peak periods are discussed to some extent as well.

To give an impression of extreme wave conditions and related features of the local wave climate, we start from an overview of the existing wave data and numerical wave studies in the NBP and the GoF. Operational wave modelling routines for this area are described next. Further on, wave data from a buoy in the NBP and from two locations in the GoF are compared with modelled wave properties. Finally, we construct an estimate of the overall maximum wave height in this storm and discuss potential reasons of the excitation of high and long waves.

\section{Wave climate in the northern Baltic Proper and the Gulf of Finland}

Many Baltic Sea countries have performed extensive wave studies in the past and have implemented operational wave models nowadays. The longest instrumental wave measurements in the NBP have been carried out in 1978-2003 by the Swedish Meteorological and Hydrological Institute with the use of an inverted echo-sounder near a caisson lighthouse of Almagrundet (Fig. 1, Mårtensson and Bergdahl, 1987; Broman et al., 2006). Wave properties at this site are determined based on the classical zero-downcrossing method. An estimate of the significant wave height $H_{1 / 3}$ (defined as the average height of $1 / 3$ of the highest waves) is found somewhat non-traditionally from the 10th highest wave in a record of about $10 \mathrm{~min}$ once an hour under the assumption that the wave heights are Rayleigh distributed. Note that contemporary measurement devices and spectral wave models use another estimate of the significant wave height $H_{S} \approx H_{1 / 3}$ defined as the fourfold variance of the water surface. The highest $H_{1 / 3}=7.82$ occurred at this site in January 1984 (Broman et al., 2006, Kahma et al., 2003 mention the value $H_{S}=7.7 \mathrm{~m}$ ) whereas the mean period (which generally is by $10-20 \%$ smaller than the peak period) reached $11 \mathrm{~s}$. This is formally the largest significant wave height ever recorded in the NBP. This storm is the only one recorded at this site when $H_{1 / 3} \geq 7 \mathrm{~m}$ was registered.

Directional wave properties in the central part of the NBP (buoy 1 in Fig. $1,59^{\circ} 15^{\prime} \mathrm{N}, 21^{\circ} 00^{\prime} \mathrm{E}$, water depth about $100 \mathrm{~m}$ ) have been measured by the FIMR starting from September 1996 excluding ice seasons. The measurement routine and an overview of wave statistics (occasionally involving observations at Almagrundet and at some other locations) are presented by Kahma et al. (2003). The highest waves with $H_{S}=7.7 \mathrm{~m}$ were recorded on 22 December 2004 at this location. The significant wave height has exceeded $7 \mathrm{~m}$ only four times at this site: twice in December 1999 and twice within three weeks - on 22 December 2004 (when the largest single wave ever recorded in the NBP has been registered with a height of $14 \mathrm{~m}$ ) and on 9 January 2005 during windstorm Gudrun. The peak periods during these events slightly exceeded $12 \mathrm{~s}$.

High-quality wave data sets have been measured by the FIMR starting from 1970s in areas surrounding Finland (Kahma et al., 1983; Kahma and Pettersson, 1993; Pettersson 1994; Pettersson, 2001; Kahma et al., 2003). A directional waverider is deployed off Helsinki in the GoF (Fig. 1, 59 $57.9^{\prime} \mathrm{N}, 25^{\circ} 14.1^{\prime} \mathrm{E}$, water depth about $60 \mathrm{~m}$, below referred to as buoy 2). The measurements have been made in 1990 1991, 1994 and from November 2001 during the ice-free seasons. The highest $H_{S}=5.2 \mathrm{~m}$ in the GoF was measured at this site in November 2001 (Pettersson and Boman, 2002; Soomere, 2005). The peak periods reached $11 \mathrm{~s}$ during this event. Practically no data are available from the coastal areas of Estonia and Latvia except for visual observations from the coast (Soomere and Zaitseva, 2007) and for sporadic measurements with the use of pressure sensors (Soomere, 2005).

The third generation wave models (e.g. Komen et al., 1994) adequately represent the sea state in the northern Baltic Sea (e.g. Tuomi et al., 1999). Several numerical wave studies have been performed for the southern part of the Baltic Sea (e.g. Gayer et al., 1995; Blomgren et al., 2001) or for limited areas of the northern Baltic Proper (Soomere, 2001; 2003) during the last decade. Recently, wave statistics for the Baltic Proper has been estimated with the use of the secondgeneration spectral wave model HYPAS and wind data from 1999-2000 (Jönsson et al., 2002; 2005). The spatial distribution of wave heights follows the local anisotropy of the wind and wave regime in the Baltic Proper (Soomere, 2003). 
Statistically, the regions of the largest wave activity are found along the eastern coasts of the Baltic Proper. These areas are characterised by long fetches for the dominant winds. The quantitative features of the results in (Jönsson et al., 2002; 2005), however, may differ from the factual ones, because these studies do not account for ice cover in a part of the northern Baltic Sea during the season that statistically contains the highest wind speeds.

A number of studies are concentrated on specific problems of the Baltic Sea wave fields such as multi-peaked wave spectra (Kahma, 1981), wave energy problems (Mårtensson and Bergdahl, 1987), possible changes of wave climate caused by changes of storminess (WASA Group, 1995), methods of estimates of wave climate (Mietus and von Storch, 1997), the persistence of wave statistics (Boukhanovsky et al., 1999), or wave climate in small semi-enclosed basins (Soomere, 2005). However, no comprehensive description of the wave climate or statistical estimates of extreme wave conditions exists in the whole Baltic Proper. Older publications such as Rzheplinsky and Brekhovskikh (1967) are obsolete. The books published in the former Soviet Union (e.g. Davidan et al., 1985) contained valuable measured wave data but were available only in Russian language.

\section{Operational wave models in the DWD, FIMR and DMI}

All the listed operational centres run the third generation spectral wave model WAM cycle 4 (Komen et al., 1994) on a regular rectangular or spherical grid in shallow water mode without data assimilation. The models use different sources of wind information and their land-sea masks, bathymetry, computational grid, spatial and temporal resolution, and spectral range are different (She and Nielsen, 1999; Soomere et al., 2004).

The regional spectral wave model LSM (Local Sea Wave Model) is used in the DWD for an area including the North Sea, the Baltic and the Adriatic Sea since 1999. Wave conditions in the Baltic Sea are independent on the sea state in other model areas. The LSM mesh size is $1 / 10^{\circ}$ along latitudes and $1 / 6^{\circ}$ along longitudes. The FIMR runs the wind and wave models for the Baltic Sea area with a $1 / 5^{\circ} \times 1 / 5^{\circ}$ resolution along since November 2001 (Järvenoja and Tuomi, 2002). The resolution was increased to $0.08^{\circ} \times 0.08^{\circ}$ just before the storm in question, from November 2004. The DMI runs since 1999 the WAM model for the North Sea and the Baltic Sea in $1 / 6^{\circ} \times 1 / 6^{\circ}$ resolution. A nested model, with $1 / 30^{\circ} \times 1 / 30^{\circ}$ resolution, is applied in the nearby Danish waters; however, no feedback from the fine model is used in the coarse model runs.

All the models are driven by forecast winds at the standard height of $10 \mathrm{~m}$ above the surface level. The LSM wave model uses three-hourly wind fields provided by the atmospheric model LM of the DWD with a mesh size of $1 / 16^{\circ} \times 1 / 16^{\circ}$.
The DMI and FIMR wave models use hourly wind data from different versions of the atmospheric model HIRLAM: the DMI-HIRLAM (horizontal resolution of $1 / 20^{\circ} \times 1 / 20^{\circ}$ ), and the Finnish Meteorological Institute's HIRLAM version 6.2.1 (horizontal resolution of $0.08^{\circ} \times 0.08^{\circ}$ ).

The WAM model calculates the two-dimensional wave energy density spectrum at each sea point for a set of equally spaced directions and logarithmically spaced frequencies. The LSM and FIMR models use 24 directions (i.e. directional resolution is $15^{\circ}$ ) whereas the DMI model uses 12 directions (resolution $30^{\circ}$ ). The spectral directions of all the models are shifted away from the major compass directions. The LSM and DMI models employ 25 frequency bands from 0.04177 to $0.41145 \mathrm{~Hz}$ (periods from about 2 to $20 \mathrm{~s}$ ) in $10 \%$ steps. The FIMR model uses an extended range of 35 bands up to $1.073 \mathrm{~Hz}$ in order to better describe shorter waves in sub-basins of the Baltic Sea.

The LSM and the FIMR models account for sea ice (areas covered by ice are coded as land) while the DMI model does not. For the storm in question this feature of the models is irrelevant, because sea ice only existed in Bothnian Bay in the area that does not influence wave fields in the NBP or in the GoF. The depth information and the land-sea mask of the LSM model are optimised for the concurrent use with a circulation model. In some northern parts of the Baltic Sea they do not exactly follow the factual coastline. For example, the area of Pärnu Bay is not represented in the model grid and the eastern part of the GoF is by and large sheltered from waves propagating from the NBP. The FIMR model accounts for special features of the northern Baltic Sea. The archipelago area between Åland and the Finnish mainland is handled by coding this area as impassable for waves. The irregularities of the shoreline and sheltering islands are accounted for by an appropriate choice of the model shoreline. The depth map of the DMI model is sampled from the ETOPO5 bathymetry map of the National Geophysical Data Centre (http://www.ngdc.noaa.gov/mgg/global/global.html) with an imposed minimum depth of $5 \mathrm{~m}$.

The LSM model provided operational forecasts for $48 \mathrm{~h}$ twice a day in January 2005. The DMI and FIMR models were run four times a day with a $54 \mathrm{~h}$ forecast length. The output of these models is called modelled wave data below. After each forecast cycle, the most important parameters of the sea state such as the significant wave height of the entire wave field, the significant wave height, the peak period and the wave direction for both windsea and swell, and optionally the mean period, and the components of the driving wind fields (wind speed, wind direction) were stored for all sea points three-hourly for the LSM and the FIMR model, and hourly for the DMI model. Spectral information was only saved for selected sea points in the FIMR model. The peak period $T_{P}$ used in comparisons below is the $1 \mathrm{D}$ peak of the directionally integrated spectrum which is equivalent to the peak period estimated by the waveriders and from the pressure data. 
Wind at $10 \mathrm{~m}(\mathrm{~m} / \mathrm{s}): 2005 \mathrm{JAN} 09$ at $06 \mathrm{z}$

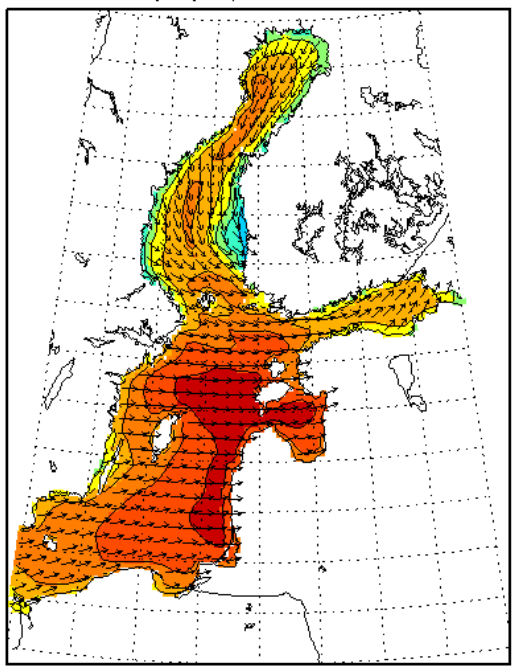

Fig. 2. Modelled wind speed $(\mathrm{m} / \mathrm{s})$ and direction (arrows) $10 \mathrm{~m}$ above water surface at 06:00 GMT on 9 January in the DMI 54-hour forecast valid at 00:00 GMT on 9 January.

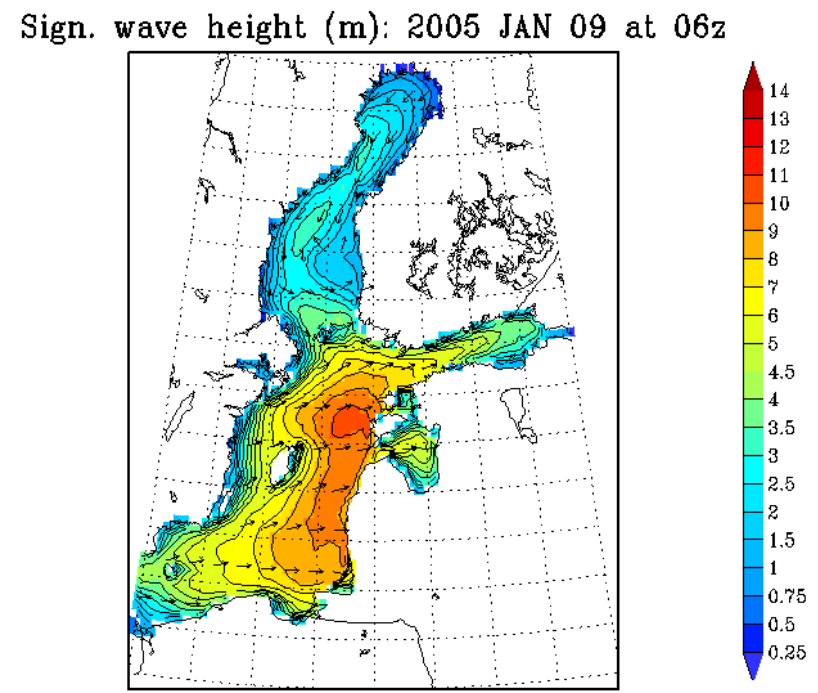

Fig. 3. Modelled significant wave height $H_{S}(\mathrm{~m})$ and wave propagation direction (arrows) at 06:00 GMT on 9 January in the DMI forecast valid at 00:00 GMT on 9 January.

To match the factual temporal resolution of all the models, comparisons are made for three-hourly wave data at 00:00, 03:00 GMT etc. at which the wave data of FIMR and the LSM models are saved. As the observation times at buoys 2 and 3 not necessarily coincide with the model output times and have certain gaps, we use the average values of the available wave data and of the DMI model output during $\pm 1.5 \mathrm{~h}$ around these time instants.
To the knowledge of the authors, no systematic validation of the models' results against measured data in the northern Baltic Sea have been reported in international literature although there is acute need for such analysis. The available information suggests that, at least in typical wave conditions, all the listed models show reasonable performance. For example, comparison of the DMI model with satellite data revealed that the overall bias and standard deviation of the significant wave height in the North Atlantic and the Baltic Sea was $0.13 \mathrm{~m}$ (the model tended to slightly overestimate the wave heights) and $0.56 \mathrm{~m}$, respectively during July 2004March 2005 (http://ocean.dmi.dk/validations/waves/satellite/ sat_valid.uk.php). The mean relative error of the forecast of the maximum wave height in the 5 strongest storms is about $15 \%$ for 13 buoys operated by the DMI in the Baltic Sea and in the North Atlantic (http://ocean.dmi.dk/validations/waves/ resultat/index.uk.php). The DWD model shows an equivalent performance. For example, the monthly bias and standard deviation in February 2003 were from -0.27 to $0.32 \mathrm{~cm}$ and from 0.3 to $0.71 \mathrm{~m}$, respectively, in 12 different buoy locations. The presented estimates well match the standard deviation of the forecast from the observed wave heights during the stormy week 7-14 January 2005 at the locations of buoys 1 and 2 (Table 1) and the relative error of the forecast of the maximum wave height during the storm maximum (see below). The reasons of somewhat larger deviations of the forecast from the observed wave heights for the location of buoy 3 are discussed below.

\section{Observed and modelled wave properties in the Baltic Proper}

Several features of wind patterns are interesting from the viewpoint of wave generation. Since the coastal data suffered from failures of equipment (Suursaar et al., 2006), we shortly describe the modelled wind properties. The maximum wind speeds on the open sea, according to the DWD and the DMI (Fig. 2), were 28-29 m/s between Gotland and Saaremaa (cf. coastal data in Suursaar et al., 2006). Wind blew from $\mathrm{W}$ in the central Baltic Proper, from WSW in the Gulf of Riga, and from W-NWN in the northernmost part of the Baltic Proper during the wave storm maximum, and thus a convergent wind pattern occurred. All forecasts suggested that strong wind was to blow during many hours. The forecasts released on 6-7 January predicted the highest wind speeds to occur along the Norrköping-Hiiumaa/Saaremaa line. The significant wave height was forecast to exceed $10 \mathrm{~m}$ at buoy 1, to reach 11-12 $\mathrm{m}$ at the entrance of the GoF, and to be over $6 \mathrm{~m}$ in the central part of this gulf. Such wave conditions would have been rougher than during any other storm in the northern Baltic Sea in the history of contemporary shipping (K. Kahma, personal communication on 8 January 2005). 
Table 1. Comparison of modelled and observed significant wave height $H_{S}$ and peak period $T_{P}$ during windstorm Gudrun (from 12:00 GMT on 08 January to 24:00 GMT on 09 January) and during the stormy week 7-14 January 2005 (until 06:00 GMT on 12 January at buoy 2, and from 08:00 GMT on 8 January at buoy 3 ) in terms the bias (model - observed) and root-mean-square (rms) error.

\begin{tabular}{llcccccc}
\hline \multicolumn{7}{c}{ Significant wave height (m) } \\
\hline \multirow{2}{*}{ Location } & \multicolumn{2}{c}{$\begin{array}{c}\text { Northern Baltic } \\
\text { Proper (Buoy 1) }\end{array}$} & $\begin{array}{c}\text { Gulf of Finland } \\
\text { Helsinki (Buoy 2) }\end{array}$ & $\begin{array}{c}\text { Gulf of Finland } \\
\text { Naissaar (Buoy 3) }\end{array}$ \\
\hline \multirow{2}{*}{ Model } & & Bias & Rms error & Bias & Rms error & Bias & Rms error \\
\hline \multirow{2}{*}{ FIMR } & Whole week & -0.363 & 0.527 & -0.232 & 0.330 & 0.324 & 0.490 \\
& Gudrun & -0.347 & 0.663 & -0.003 & 0.222 & 0.661 & 0.856 \\
DMI & Whole week & 0.386 & 0.587 & 0.155 & 0.419 & 0.714 & 0.864 \\
& Gudrun & 0.865 & 1.063 & 0.404 & 0.638 & 1.119 & 1.306 \\
DWD & Whole week & 0.242 & 0.458 & -0.255 & 0.388 & 0.587 & 0.825 \\
& Gudrun & 0.703 & 0.829 & -0.053 & 0.379 & 1.119 & 1.329 \\
\hline \multirow{2}{*}{ FIMR } & Whole week & -0.604 & 0.904 & -1.146 & 1.685 & -0.738 & 1.170 \\
& Gudrun & -0.701 & 1.145 & -1.156 & 1.662 & -1.274 & 1.527 \\
\multirow{2}{*}{ DMI } & Whole week & 0.372 & 0.662 & 0.182 & 1.211 & 0.260 & 0.785 \\
& Gudrun & 0.328 & 0.979 & -0.263 & 1.682 & 0.004 & 1.130 \\
& Whole week & -1.270 & 1.588 & -2.586 & 2.974 & -1.965 & 2.490 \\
& Gudrun & -1.244 & 1.492 & -2.407 & 2.826 & -1.399 & 1.793 \\
\hline
\end{tabular}

The low pressure area, in fact, propagated less northwards after crossing Norway and Sweden (Carpenter, 2005, see also analysis of the path of the cyclone and of the strongest winds in Suursaar et al., 2006, or (http://www.emhi.ee/index.php? ide $=2 \&$ shownews $=18$ ). The area with the largest modelled wind speeds crossed Gotland, the northern part of Latvia and the Gulf of Riga, southwards from the location of buoy 1. The highest waves were excited off Saaremaa and Latvia (Fig. 3).

The measured wave heights did not establish any new records. The significant wave height at buoy 1 reached $H_{S}=7.2 \mathrm{~m}$ at 03:00 and 07:00 GMT on 9 January (Fig. 4). The wave height was about $7 \mathrm{~m}$ during about $12 \mathrm{~h}$ (00:0011:00 GMT). The FIMR model well matched the roughest wave conditions in the early morning of 9 January (Fig. 4a, Table 1). The overall maximum of $H_{S}$ was overestimated by $0.44 \mathrm{~m}(5.8 \%)$. The wave storm decayed somewhat more slowly than suggested by the model. The FIMR model also underestimated by about $1 \mathrm{~m}$ (about 20\%) the wave height on 13 January. The models of the DWD and the DMI to some extent overestimated the wave heights during the whole stormy week (Table 1). The largest error (1.29 $\mathrm{m}$ and $1.91 \mathrm{~m})$ of the instantaneous wave height occurred during a short time interval when the modelled wave height reached its maximum but the factual wave heights dropped by about $0.6 \mathrm{~m}$. The error of the modelled overall maximum wave height $(8.17$ and $8.96 \mathrm{~m})$ was $12.4 \%$ and $20.1 \%$, respectively, for the DWD and DMI models.

The windsea peak period $T_{P}$ at buoy 1 exceeded $10 \mathrm{~s}$ for nearly $24 \mathrm{~h}$ and was about $11-12 \mathrm{~s}$ when the wave height was close to $7 \mathrm{~m}$ (Fig. 4b). Both the DMI and the FIMR models well reproduced its temporal behaviour (Fig 4b, Table 1). The period calculated by the DMI model behaved in a steplike manner, because no interpolation in space, time or in spectral space was done. The DWD model systematically underestimated the wave periods by $1-1.5 \mathrm{~s}$. This feature also caused the large root-mean-square error of the peak period predictions. Notice that the overall performance of the models during windstorm Gudrun is approximately the same as during the entire stormy week 7-14 January 2005 (Table 1). It is interesting to mention that the FIMR and the DWD models almost perfectly reproduced the wave heights at buoy 2 specifically during Gudrun.

The modelled peak periods were somewhat higher, about $12-14 \mathrm{~s}$, in the north-eastern part of the Baltic Proper during a long time. Since the wind direction in the Baltic Proper probably changed from south to west as the cyclone gradually crossed the sea, a part of long waves in the north-eastern area of the Baltic Proper apparently were excited by more south-western winds in the early stage of the storm. Yet the above-described match between the observed and modelled peak periods at buoy 1 suggests that remarkably long and high waves eventually occurred in some sea areas.

\section{Waves in the Gulf of Finland}

Wave properties in the GoF were measured at two sites (Fig. 1). Off its southern coast, the Institute of Cybernetics used a domestic wave recorder (PTR Group) based on Keller 

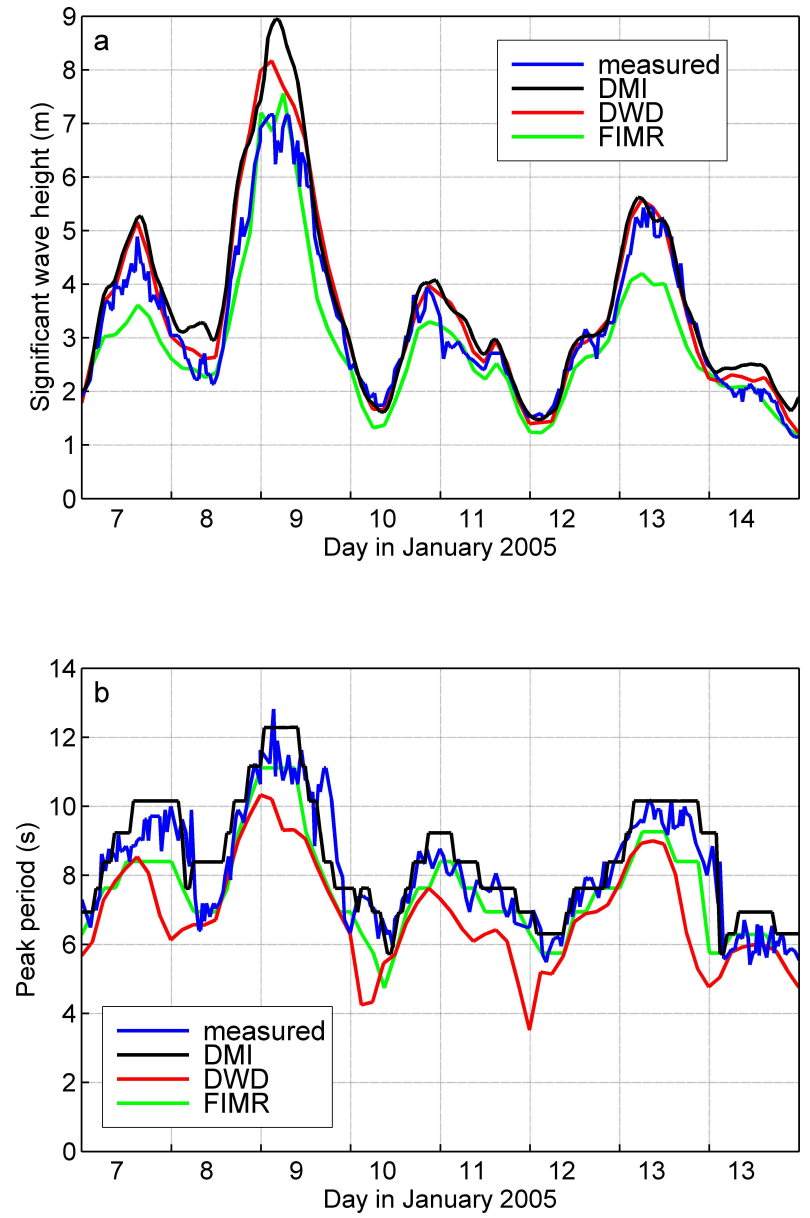

Fig. 4. (a) Significant wave height (m) and (b) peak period (s) at the location of the FIMR buoy 1 in the NBP $\left(59^{\circ} 15^{\prime} \mathrm{N}, 21^{\circ} 00^{\prime} \mathrm{E}\right)$ as observed (blue) and modelled by the DWD (red), FIMR (green) and DMI (black).

pressure sensor and mounted about $8 \mathrm{~m}$ below the water surface, to record this event. The site $\left(59^{\circ} 37.1^{\prime} \mathrm{N}, 24^{\circ} 29.1^{\prime} \mathrm{E}\right.$, water depth about $14 \mathrm{~m}$, below called buoy 3 ) is located north-westwards from the Island of Naissaar. The pressure data was recorded with a frequency of $4 \mathrm{~Hz}$ and analysed with the use of the classical procedure of establishing the surface wave properties from the pressure time series based on the linear wave theory (e.g. Stumbo et al., 1999). Wave properties in record sections with duration of 20 min were calculated from the truncated wave energy density. The waves with periods $<3 \mathrm{~s}$ were ignored. For comparisons below the mean wave properties over 3-h time intervals are used.

The observed $H_{S}$ exceeded $4 \mathrm{~m}$ at 02:00 GMT on 9 January and remained about $4 \mathrm{~m}$ during many hours (Fig. 5a). The maximum wave height $(4.5 \mathrm{~m}$, the second highest instrumentally registered wave height in the central part of the GoF) occurred at 09:00 GMT on 9 January. Wave properties at this site are not directly comparable with the mod- elled data because the closest model grid point (in the FIMR model) is located in a much deeper area about $10 \mathrm{~km}$ from buoy 3. The reason is an unfortunate mismatch of the geometry of the coastline and the mesh in the relatively low resolution of the operational model: the centre of the most seaward land point lies only slightly landward from the factual coastline and from this temporary measurement site. Putting the grid points closer to the island in this resolution would lead to unrealistic fetches and unrealistic significant wave heights. Thus it is not unexpected that the modelled wave heights at the closest grid points did not match the observed values. Still all three models followed the measured sea state qualitatively. The FIMR model suggested the maximum $H_{S} \approx 5.5 \mathrm{~m}$ and captured even the minor wave height maximum at 02:00 GMT. For another wave storm on 13 January it predicted somewhat earlier appearance of high waves. The DWD and DMI models predicted that the overall wave height maxima at this site were close to or even exceeding $6 \mathrm{~m}$. The analysis below suggests that these values probably were not reached.

The observed peak periods exceeded $10 \mathrm{~s}$ during a large part of the 9 January at buoy 3 and were close to $12 \mathrm{~s}$ during about $10 \mathrm{~h}$ (Fig. 5b). Visual observations by one of the authors (TS) in the morning of 9 January from high cliffs of the peninsula of Pakri (located about $30 \mathrm{~km}$ south-eastwards from buoy 3) confirmed that the periods of the largest beaching waves were well over $10 \mathrm{~s}$. The DMI wave model mostly captured this feature (Table 1). The FIMR model qualitatively followed the temporal behaviour of $T_{P}$ but underestimated by about $1 \mathrm{~s}$ the longest wave periods during Gudrun. The DWD model systematically underpredicted the peak periods by $1.5-2 \mathrm{~s}$.

The other wave measurement site (buoy 2) was located in the northern part of the GoF off Helsinki $\left(59^{\circ} 58.5^{\prime} \mathrm{N}\right.$, $\left.25^{\circ} 14^{\prime} \mathrm{E}\right)$. The FIMR operated a directional waverider at this site until 12 January. Since this site is more remote from the Baltic Proper than Naissaar, it is not unexpected that both the wave heights and peak periods were slightly smaller than at Naissaar (Fig. 6). The observed wave height was close to $4 \mathrm{~m}$ during a short time interval in the early morning of 9 January and exceeded $3 \mathrm{~m}$ during the rest of the day. The FIMR and the DWD models well reproduced (but the DMI model somewhat overpredicted) the observed wave heights during the maximum of the wave storm.

The observed peak periods near Helsinki exceeded $10 \mathrm{~s}$ during nearly the whole day and reached $11-12 \mathrm{~s}$ at noon on 9 January (Fig. 6b). The modelled peak periods did not exceed $9 \mathrm{~s}$ and generally were less than $8 \mathrm{~s}$. The DMI model mostly captured the temporal behaviour of $T_{P}$ also at this site (Table 1). The FIMR model underpredicted the peak periods by about $1 \mathrm{~s}$ and the DWD model by $2.5 \mathrm{~s}$.

The occurrence of long and high waves in the interior of the GoF is an important feature of this storm. Early wave measurements have suggested that the peak periods in rough seas are $8-9 \mathrm{~s}$ and usually do not exceed $10 \mathrm{~s}$ in the GoF 

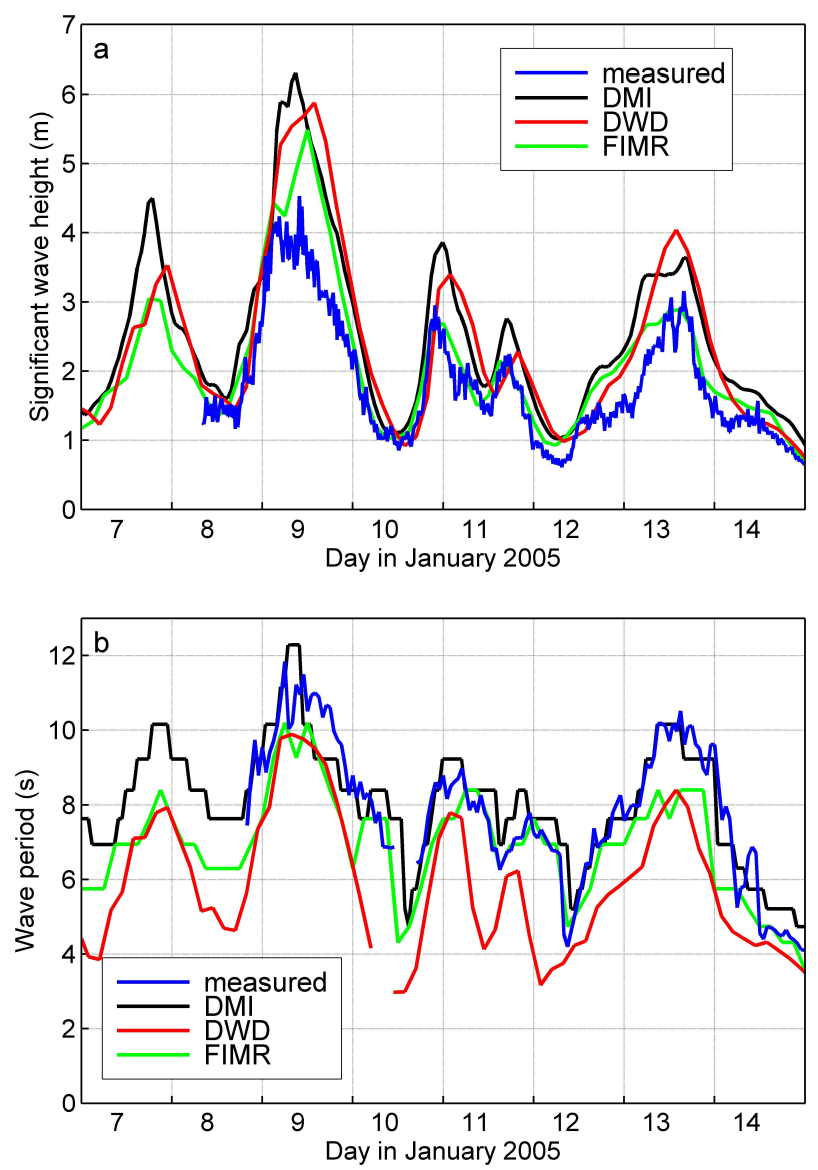

Fig. 5. (a) Significant wave height (m) and (b) peak period at the location of buoy 3 near the Island of Naissaar in the Gulf of Finland $\left(59^{\circ} 37,1^{\prime} \mathrm{N}, 24^{\circ} 29,1^{\prime} \mathrm{E}\right)$ as observed (blue, hourly mean values of peak periods are shown) and modelled by the DWD (red), FIMR (green) and DMI (black). Only observed periods clearly exceeding the threshold period ( $3 \mathrm{~s})$ are shown.

(Kahma and Pettersson, 1993). More recent observations indicate that $T_{P} \approx 11 \mathrm{~s}$ may occur in this area (Pettersson, 2001). Yet the rough seas, with $H_{S} \sim 4 \mathrm{~m}$, have peak periods of about 8-9s. The number of observations of even larger peak periods is small: $T_{P} \approx 11 \mathrm{~s}$ were filed only three times during measurements in 1990-1994 (probably during one storm) and occurred during a short time during another very strong storm in November 2001. The distribution of the frequency of occurrence of peak periods (Pettersson, 2001) suggests that $T_{P} \geq 10 \mathrm{~s}$ usually corresponds to penetration of long-period swell of moderate height from the NBP to the GoF (cf. Broman et al., 2006).

The modelled maximum wind speed in the northernmost part of the Baltic Proper and at the entrance of the GoF was about 20-24 m/s during Gudrun (Fig. 2). In the gulf it apparently was well below $20 \mathrm{~m} / \mathrm{s}$ during a large part of the storm (see also coastal data in Suursaar et al., 2006). The moderate water depth $(50-80 \mathrm{~m})$ of the western part of the gulf reduces
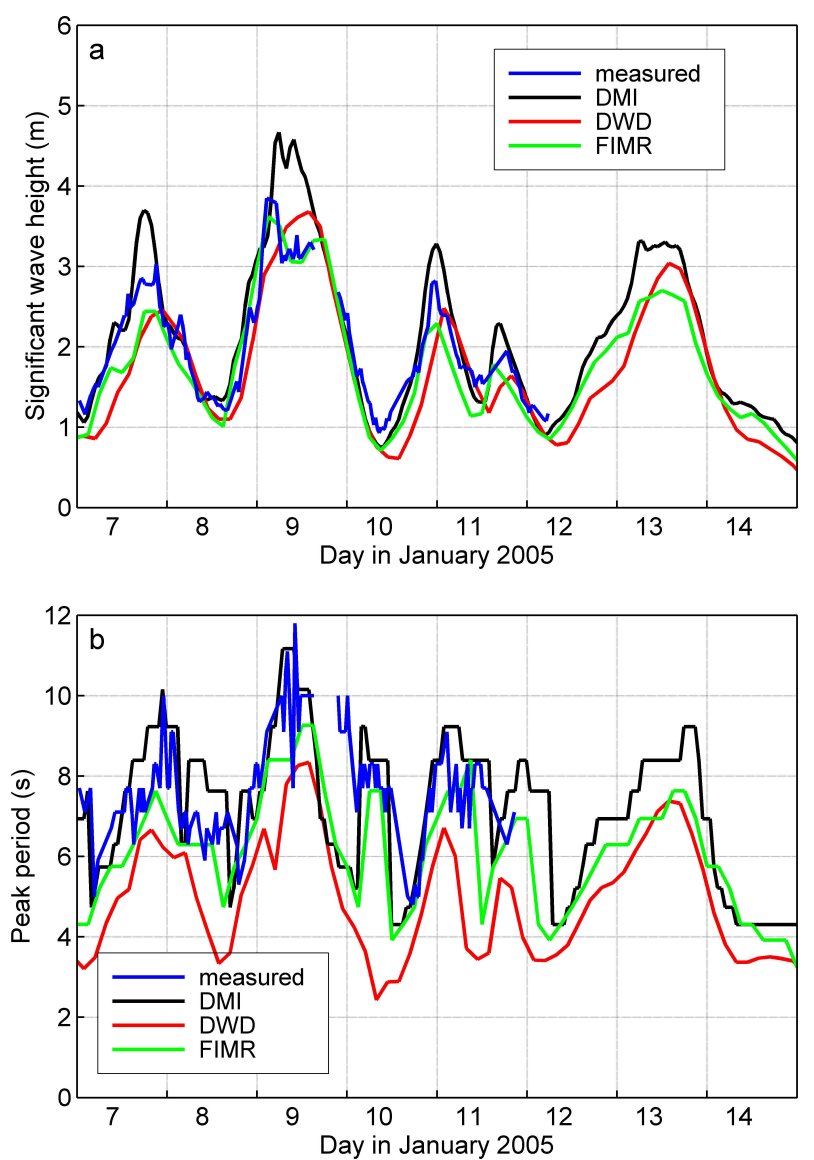

Fig. 6. (a) Significant wave height (m) and (b) peak period (s) near Helsinki as observed at the location of FIMR buoy 2 (blue) and modelled by the DWD (red), FIMR (green) and DMI (black). There is a gap in measured data at 15:30-21:30 on 9 January.

the celerity of long waves (which is about $20 \mathrm{~m} / \mathrm{s}$ for deep water waves with periods about $12 \mathrm{~s}$ ). Although transfer of energy of long waves to atmospheric motions (e.g. Kudryavtsev and Makin, 2004) is generally quite small, one may assume that the wind was mostly faster than the dominating waves and such transfer was negligible in the GoF.

For such wind speeds the observed wave periods in the interior of the GoF were very large. Classical estimates of the wave growth in fetch-limited seas suggest that storms with a wind speed of about $20 \mathrm{~m} / \mathrm{s}$ may excite peak periods about 12 s only if the fetch length is $\geq 600 \mathrm{~km}$ and the wind duration $\geq 18 \mathrm{~h}$ (e.g. Rosenthal, 1986). Although recent growth curves (Kahma and Calkoen, 1992; Komen et al., 1994) suggest that somewhat shorter duration (about $15 \mathrm{~h}$ ) and fetch (about $350 \mathrm{~km}$ ) are sufficient for generation of such seas, it is probable that a portion of long waves stemming from the Baltic Proper contributed to the observed wave system in the GoF. Long waves propagating from the southern parts of the Baltic Proper are refracted by the coastal slope of Hiiumaa 
(a large island northwards from Saaremaa) which turns them to the right and (for a certain combination of wave periods and propagation directions) may guide waves exactly into the gulf. This effect only works for waves approaching from SW because the archipelago north-westwards from the entrance of the GoF is almost impassable for waves.

\section{Maximum of the wave storm}

The above has shown that the wave storm maximum evidently occurred much southwards from buoy 1 . The modelled wind speed had considerable North-South gradient (Fig. 2). There were quite large differences (up to 6\% according to the DMI model) in the modelled wave heights at certain adjacent grid points in the North-South direction in the NBP. This feature suggests that the wave field contained particularly strong N-S gradients and that the overall maximum wave height apparently was larger than at the measurement site. For single sea points the forecast wave heights varied considerably as the new releases became available because of a certain deflection of the trajectory of the windstorm. Yet the forecast of the overall maximum wave height in the whole Baltic Sea showed a reasonable variation, for example, it was between 10.8 and $12.2 \mathrm{~m}$ according to the DMI model.

The overall maximum $H_{S}$ in the NBP and in the GoF during this storm can be roughly estimated from a comparison of the modelled spatial distributions of wave properties with the modelled and observed wave heights. It eventually occurred off the coast of Saaremaa (Fig. 3) about $57^{\circ} \mathrm{N}$, $20.4^{\circ} \mathrm{E}$, that is, about $200 \mathrm{~km}$ south-eastwards from the location of buoy 1 . Assuming that (i) the wave models adequately represent the spatial patterns of wave properties and (ii) that the relative error of the modelled wave properties is roughly the same in the whole area of intense waves; the estimate can be obtained by correcting the overall maximum of the modelled $H_{S}$ by the relative error of the model at the measurement site. The results of doing so based on observations in one point only should be interpreted as indicative: the accuracy of the forecast may vary in different parts of the Baltic Proper; especially in the case when the wind direction turns in the NBP as usually happens during strong cyclones. Yet this is a feasible way to estimate the maximum wave heights during the storm given the limited data set. Since a large part of properties of the wave fields represented in Figs. 4-6 are located within the 'corridors' formed by outputs of the three models, a reasonable estimate of this maximum eventually lies between the values defined by the three models. The above has shown that the discussed wave models reasonably followed the temporal behaviour of wave fields in the NBP. Their accuracy did not change much during the whole stormy week and matched the available error statistics. Thus the listed assumptions are sensible.

The FIMR wave model suggested that $H_{S}$ up to $10.2 \mathrm{~m}$ occurred near Saaremaa on 9 January. Since it overesti- mated the maximum of $H_{S}$ at buoy 1 by $5.8 \%$, the probable maximum of $H_{S}$ was $9.6 \mathrm{~m}$. The DMI model suggested that $H_{S}=11.7 \mathrm{~m}$ occurred in the same area; accounting for its overestimation at buoy 1 by $20.1 \%$ gives the probable maximum of $H_{S} \approx 9.4 \mathrm{~m}$. The DWD model predicted the overall maximum of $H_{S}$ about $10.95 \mathrm{~m}$ on 9 January. At buoy 1 this model gave maximum $H_{S}=8.17 \mathrm{~m}$ and the overestimation of $12.4 \%$, respectively. The estimate for the overall maximum of $H_{S}$ in the Baltic Proper therefore is $9.6 \mathrm{~m}$.

The relatively small scatter of the estimates suggests that the overall maximum of $H_{S}$ in the Baltic Proper during windstorm Gudrun most probably was about $9.5 \mathrm{~m}$. The significant wave height eventually was well over $9 \mathrm{~m}$ in a considerable part of the Baltic Proper. It is unlikely that the threshold of $10 \mathrm{~m}$ was exceeded.

Analogous reconstruction of the maximum wave height in the GoF is not straightforward. The site near Naissaar was located at a considerably smaller depth than the closest model point and it is not obvious how to account for shallow-water effects in this area with quite a complex geometry and bathymetry. The FIMR deep-water measurement site off Helsinki offers a better ground for comparison. Application of the above-described procedure suggests that $H_{S}$ slightly exceeded $5 \mathrm{~m}$ but most probably did not considerably exceed the historical maximum $H_{S}=5.2 \mathrm{~m}$ between Helsinki and Tallinn.

\section{Results and discussion}

The strong reaction of the water surface to windstorm $\mathrm{Gu}$ drun both in terms of sea level and high and long waves is the most interesting feature of this event, creating substantial hazards both onshore and offshore. The maximum sustained wind speed (about $29 \mathrm{~m} / \mathrm{s}$ in the Baltic Proper) was large but not exceptional. Also, the modelled strongest wind direction (from the West) was not particularly favourable for wave generation: the effective fetch was about a half of that for SW winds. Yet Gudrun excited very high and long waves. The central outcome of the above analysis is that that the overall maximum of $H_{S}$ evidently exceeded $9 \mathrm{~m}$ off coasts of Saaremaa and Latvia and most probably was about $9.5 \mathrm{~m}$ in some areas. Such wave heights were unexpected based on the existing wave statistics from the northern Baltic Proper.

It might be speculated that a future storm of the same strength and duration, but corresponding to more favourable wave generation conditions, may create even higher waves. Very high waves may occur in the NBP when a strong and large cyclone (that is able to create a practically homogeneous wind field over the whole Baltic Proper for a long time) travels in the NNE direction. Since only a few cyclones do so (Suursaar et al., 2006), such a "perfect storm" is not likely to occur. However, if it would happen, it would contain a considerably longer fetch and probably would excite even rougher wave conditions at the entrance of the GoF and off 
the south-western coast of Finland than Gudrun near Saaremaa.

It is not straightforward to identify which feature of Gudrun is responsible for the generation of the above-described wave fields. As discussed in Sect. 4, the wind direction in the Baltic Proper apparently changed as the cyclone gradually crossed the sea and a part of wave energy in the area of the roughest seas eventually was excited by more southwestern winds corresponding to longer fetches. Also, the spatial distribution of the modelled wind speed (Fig. 2) suggests that, at least, during a certain time interval the wind field had a convergent pattern that also may result in wave energy concentration in some areas. For the pattern in Fig. 2 the highest waves eventually occur near Saaremaa. Notice that NW winds over the land archipelago visible in Fig. 2 insignificantly contribute to the wave field in the northern Baltic Proper, because most of the archipelago is practically impassable for waves.

The wind direction in a large part of Gudrun was oblique with respect to the axis of the Baltic Proper; thus so-called slanted fetch situation occurred (The SWAMP Group 1985, Ch. 8). If an oblique wind pattern persists during a long time, a system of long waves propagating along the coastline emerges (Holthuijsen, 1983). At times it may form the main spectral peak. A frequently used explanation of this phenomenon is that the effective fetch for certain wave components in such conditions may be much longer than the downwind distance from the coast. This phenomenon actually is supported by nonlinear interactions as well. It frequently occurs in the GoF (Kahma and Pettersson, 1994; Pettersson, 2004) in which a part of the dominating winds are slanted with respect to the coastline (Soomere and Keevallik, 2003). To the knowledge of the authors, this phenomenon has never been analysed in the Baltic Proper where the dominating winds mostly are aligned along the axis of the basin. Its contribution to the wave field is very similar to that of a convergent wind pattern.

Another interesting feature of windstorm Gudrun is that very long and high waves also appeared in the interior the GoF, an area which generally is somewhat sheltered from long waves excited in the Baltic Proper. It is debatable if they were excited by west wind in the NBP at the latitudes of the GoF or whether they represented a part of long waves excited in the more southern areas of the Baltic Proper possibly by higher wind speeds over a longer fetch. The combination of such waves with uncommonly high water level is a probable reason for extensive damage to certain beaches, smaller harbours and jetties in sea areas where such long waves are uncommon (Orviku, 2006). For the above-described 'perfect storm' the direct excitation of a similar combination by wind in the inner part of the GoF is not likely, because the wind direction is largely different from the axis of the gulf. However, topographic refraction may still redirect a part of waves approaching from SW into the gulf.

The comparison of modelled and observed wave data shows that the basic features of wave fields during windstorm Gudrun as well as during the following stormy period were mostly well captured by operational wave models. They only tended to either somewhat overestimate the wave height or to underestimate the wave periods. An important feature is that the observed properties of the roughest windseas were generally found between the values predicted by different models. Consequently, a "poor man's ensemble modelling" (which can also be called consensus forecast) based on the comparison of predictions of different models and analysis of their performance in extreme conditions might give a reasonable forecast for the future storms. This forecast method is well known in meteorology where it is used for more exact determining of particularly sensitive parameters such as the position or trajectory of tropical cyclones (Weber, 2005), or potential location of floods (Chowdhury, 2005), and where it has led to clear improvements of the forecast skill. Its application in the forecast of mostly wind-induced marine hazards such as extreme water levels and storm surges is straightforward. The performed analysis suggests that this method is also applicable in predictions of hazardous wave conditions in cooperation of operational services.

Acknowledgements. This study has been mostly performed when one of the authors (TS) was visiting the Institute for Coastal Research, GKSS Forschungszentrum, in the framework of the re-invitation programme of the Alexander von Humboldt Foundation. The work was financially supported by the Estonian Science Foundation (Grant 5762 and 7413), EU-supported INNOVE project 1.0101-0208, and Marie Curie RTN network SEAMOCS (MRTN-CT-2005-019374). The study was finalized when one of the authors (TS) was visiting the Centre of Mathematics for Applications, University of Oslo in the framework of the Marie Curie ToK project CENS-CMA (MC-TK-013909). The permission of the Marine Systems Institute to use their wave measurement device is gratefully acknowledged. The authors thank G. Gayer and the anonymous reviewers for useful comments and suggestions.

Edited by: A. Mugnai

Reviewed by: two anonymous referees

\section{References}

Bengtsson, A., Nilsson, C.: Extreme value modelling of storm damage in Swedish forests, Nat. Hazards Earth Syst. Sci., 7, 515521, 2007,

http://www.nat-hazards-earth-syst-sci.net/7/515/2007/.

Blomgren, S., Larson, M., and Hanson, H.: Numerical modelling of the wave climate in the southern Baltic Sea, J. Coastal Res., 17, 342-352, 2001.

Boukhanovsky, A. V., Lavrenov, I. V., Lopatoukhin, L. J., Rozhkov, V. A., Divinsky B. V., Kos'yan, R. D., Ozhan, E., and Abdalla, S.: Persistence wave statistics for Black and Baltic seas, in: Proceedings of the International MEDCOAST Conference on Wind and Wave Climate of the Mediterranean and the Black Sea, Antalya, Turkey, 9-13 November 1999, 199-210, 1999.

Broman, B., Hammarklint, T., Rannat, K., Soomere, T., and Valdmann, A.: Trends and extremes of wave fields in the north- 
eastern part of the Baltic Proper, Oceanologia, 48(S), 165-184, 2006.

Carpenter, G.: Windstorm Erwin/Gudrun - January 2005. Specialty Practice Briefing, Issue No 2., http://www.guycarp.com/portal/ extranet/pdf/Speciality_Briefing_170105.pdf, 14 pp., 2005, last access: 9 December 2007.

Chowdhury, M. R.: Consensus seasonal Flood Forecasts and Warning Response System (FFWRS): An alternate for nonstructural flood management in Bangladesh, Environ. Manage., 35, 716$725,2005$.

Davidan, I. N., Lopatoukhin, L. I., Rozhkov, V. A.: Wind waves in the world oceans, Gidrometeoizdat, Leningrad, 256 pp. 1985.

Gayer, G., Günther, H., and Winkel, N.: Wave climatology and extreme value analysis for the Baltic Sea area off the Warnemünde harbour entrance, Deutsche Hydrographische Zeitschrift, 47, 109-130, 1995.

Holthuijsen L. H.: Observations of the directional distribution of ocean wave energy in fetch limited conditions, J. Phys. Oceanogr., 13, 191-207, 1983.

Järvenoja, T. and Tuomi, L.: Coupled atmosphere-wave model for FMI and FIMR, HIRLAM Newsletter, 40, 9-22, 2002.

Jönsson, A., Broman, B., and Rahm, L.: Variations in the Baltic Sea wave fields, Ocean Eng., 30, 107-126, 2002.

Jönsson, A., Danielsson, A., and Rahm, L.: Bottom type distribution based on wave friction velocity in the Baltic Sea, Cont. Shelf Res., 25, 419-435, 2005.

Kahma, K.: On two-peaked wave spectra, Finnish Marine Research, 248, 87-116, 1981.

Kahma, K. and Calkoen, C. J.: Reconciling discrepancies in the observed growth of wind-generated waves, J. Phys. Oceanogr., 22, 1389-1405, 1992.

Kahma, K. and Pettersson, H.: Wave statistics from the Gulf of Finland, Finnish Institute of Marine Research, Internal report 1/93, 27 pp., 1993.

Kahma, K. and Pettersson, H.: Wave growth in a narrow fetch geometry, The Global Atmosphere and Ocean System, 2, 253-263, 1994.

Kahma, K., Pettersson, H., and Tuomi, L.: Scatter diagram wave statistics from the northern Baltic Sea, MERI - Report Series of the Finnish Institute of Marine Research, 49, 15-32, 2003.

Kahma, K., Rantanen E., and Saarinen, J.: Wave data from the southern Bothnian Sea 1973-1975, 1981. Finnish Institute of Marine Research, Internal report 1/83, 26 pp., 1983.

Komen, G. J., Cavaleri, L., Donelan, M., Hasselmann, K., Hasselmann, S., and Janssen, P. A. E. M.: Dynamics and modelling of ocean waves, Cambridge University Press, Cambridge, 532 pp., 1994.

Kudryavtsev, V. N. and Makin, V. K.: Impact of swell on the marine atmospheric boundary layer, J. Phys. Oceanogr. 34, 934949, 2004.

Mårtensson, N. and Bergdahl, L.: On the wave climate of the southern Baltic, Report series A15, Department of Hydraulics, Chalmers University of Technology, Göteborg, 63 pp., 1987.

Mietus, M. and von Storch, H.: Reconstruction of the wave climate in the Proper Baltic Basin, April 1947-March 1988, GKSS Report 97/E/28, Geesthacht, 30 pp., 1997.

Orviku, K.: Developmental ties between Järve-Mändjala beach and Nasva harbour, Proc. Estonian Maritime Academy, 3, 7-18, 2006.
Pettersson, H.: Directional wave statistics from the southern Bothnian Sea 1992, Finnish Institute of Marine Research, Internal report 1994(5), 23 pp., 1994.

Pettersson, H.: Directional wave statistics from the Gulf of Finland 1990-1994, MERI - Report Series of the Finnish Institute of Marine Research, 44, 1-37, 2001.

Pettersson, H.: Wave growth in a narrow bay. PhD Thesis, Finnish Institute of Marine Research, Contributions no. 9, Helsinki, 33 pp. +4 articles, 2004.

Pettersson, H. and Boman, H.: High waves and sea level during the November storm, in: Annual report 2001, Finnish Institute of Marine Research, Helsinki, 7, 2002.

Rosenthal, W.: Wind waves and swell, in: Oceanography, vol. 3C, edited by: Sündermann, J., Landolt-Börnstein: Numerical Data and Functional Relationships in Science and Technology - New Series, Springer, 17-36, 1986.

Rzheplinsky, G. V. and Brekhovskikh, Y. P.: Wave atlas for Gulf of Finland, Gidrometeoizdat, Leningrad, 1967.

She, J. and Nielsen, J. W.: Operational Wave Forecasts Over Baltic and North Sea, Scientific Report 99-7, Danish Meteorological Institute, Copenhagen, Denmark, 1999.

Simpson, R. H. and Riehl, H.: The hurricane and its impact, Lousiana State Univ. Press, Baton Rouge, 398 pp., 1981.

Soomere, T.: Wave regimes and anomalies off north-western Saaremaa Island, Proc. Estonian Acad. Sci. Eng., 7, 157-173, 2001.

Soomere, T.: Anisotropy of wind and wave regimes in the Baltic Proper, J. Sea Res., 49, 305-316, 2003.

Soomere, T.: Wind wave statistics in Tallinn Bay, Boreal Env. Res., 10, 103-118, 2005.

Soomere, T., Dick, S., Gästgifvars, M., Huess, V., and Nielsen J. W.: Project plan for implementation of interfacing between Baltic scale models to local (coastal area) models, http://www.boos.org/fileadmin/user_upload/PAPA_Reports/ PAPA_ImplementationInterfacingBalticScaleToLocalModels. pdf, 22 pp., 2004, last access: 9 December 2007.

Soomere, T. and Keevallik, S.: Directional and extreme wind properties in the Gulf of Finland, Proc. Estonian Acad. Sci. Eng., 9, 73-90, 2003.

Soomere, T. and Zaitseva, I.: Estimates of wave climate in the northern Baltic Proper derived from visual wave observations at Vilsandi, Proc. Estonian Acad. Sci. Eng., 13, 48-64, 2007.

Stumbo, S., Fox, K., Dvorak, F., and Elliot, L.: The prediction, measurement, and analysis of wake wash from marine vessels, Marine Technol., 36, 248-260, 1999.

Suursaar, Ü., Kullas, K., Otsmann, M., Saaremäe, I., Kuik, J., and Merilain M.: Cyclone Gudrun and modelling its hydrodynamic consequences in the Estonian coastal waters, Boreal Env. Res., 11, 143-159, 2006.

The SWAMP Group: Ocean wave modelling, Plenum Press, New York, 262 pp., 1985.

Tuomi, L., Pettersson, H., and Kahma, K.: Preliminary results from the WAM wave model forced by the mesoscale EUR-HIRLAM atmospheric model, MERI - Report series of the Finnish Institute of Marine Research 40, 19-23, 1999.

WASA Group: The WASA project: changing storm and wave climate in the northeast Atlantic and adjacent seas? GKSS Report 96/E/61, Geesthacht, 1995.

Weber, H. C.: Probabilistic prediction of tropical cyclones, Part I: Position, Mon. Weather Rev., 133, 1840-1852, 2005. 